\title{
STANDARDS OF SEROLOGICAL CURE WITH SPECIAL REFERENCE TO NEURO-SYPHILIS
}

\author{
By J. ERNEST NICOLE, L.M.S.S.A., D.P.M. \\ Medical Superintendent, Winwick Mental Hospital, Warrington
}

Modern progress in the treatment of neuro-syphilis has brought into prominence the problem of deciding what is the serological evidence of cure. There is little difficulty in connexion with well accepted tests like the Lange, the cell-count, the protein estimation, because any deviation from the findings accepted as normal is taken to denote lack of complete cure. Not so simple, however, is the question of the " specific" "tests, for there is not any general agreement as to the tests and methods to adopt. The results of one observer are often not comparable with those of another unless full details are available concerning the tests used. For instance, the incidence of cure may be given as 80 per cent by one writer because in his series of cases only 20 per cent still have positive Wassermann reactions whereas another writer, with a similar series of cases, returns his cures as 40 per cent because he happens to dislike the Wassermann test and pins his faith to the Kahn or the Meinicke test. In fact, what is wanted is a uniform standard and method for establishing what is and what is not a serological cure, but this cannot be done until we are all agreed as to the tests to be employed : either one test, or any one of a group of tests with similar efficiency. Above all, what is most necessary is that the best tests should be accepted and recognized, and the poorest disregarded. It would be useful, too, to retain some intermediate test which might be useful in marking the stage at which a very satisfactory degree of improvement has been achieved, one beyond which it may not be essential perhaps to proceed, even although a complete cure has not resulted.

Assessing the value of syphilitic tests

On the question of assessing the comparative merits of tests for syphilis much has been said already by countless workers, and not least by the present writer. Hitherto, however, there have been two major difficulties in bringing out to the full the differences between one test and another. First, the syphilitic patients on whom the tests were applied to determine sensitivity often included a very high proportion of untreated persons in which any reliable test should give a "doubleplus " result ; consequently such failures as did occur were almost unnoticed in the mass of successes. Secondly, in estimating specificity and the occurrence of false positives in supposedly non-syphilitic cases, it often happened that the benefit of the doubt was given to the patient and not to the test which gave an unexpected positive result not backed by clinical history. Thus the positive result was called a "false positive " although the "falseness " could not be proved and might, in many cases, have been the only evidence of an old unsuspected infection.

To overcome these pitfalls it would be necessary when investigating comparative sensitivity to consider treated cases only, that is to say cases in which a high proportion of negative results, with all tests, is to be expected and in which, too, a single positive reaction can be looked upon as correct, owing to the requisite history of syphilis being always present. Until now the main difficulty has been the fact that the spinal fluid of treated patients does not tend to give negative results until several years after treatment, and as the malarial therapy of neuro-syphilis was not in vogue to any extent until after 1923 it is therefore only recently that cases have become available for examination five, ten, fifteen or more years after malaria. Even so, it is often impossible to trace the discharged patients and the task of examining a number of post-malarial patients is slow and arduous. Some information, although necessarily limited, has been obtained and is presented briefly below.

\section{Results of tests in treated neuro-syphilis}

Over 400 patients have been subjected to therapeutic malaria (with or without 
the addition of drugs) and some 200 of them have been serologically examined at least once after their treatment. Many have been re-examined several times, usually at intervals of one to four years, never more than once in any given postmalarial year, and 85 of the examinations have been done in the later periods, from the tenth to the twentieth year after the original malaria. Altogether $\mathbf{4 4 0}$ examinations of both spinal fluid and blood have been carried out and more often than not several tests have been used, but as the tests were applied in varying combinations it has been necessary to give the results in groups, corresponding to the number of combinations in which the tests were employed.

Spinal fluid results.-Let us take the spinal fluid results first. A routine Kahn test was applied in 220 instances and the number of positive results obtained was 135 , giving a sensitivity of 61.2 per cent ; the fluids were taken mostly from patients treated a long time ago. In another group of 93 spinal fluids, somewhat similar to those of the first group, the Wassermann test was applied as well as the $\mathrm{Kahn}$, and whereas the latter gave a sensitivity of 65.6 per cent the former gave only 52.7 per cent of positive results. The third group, of 127 examinations, involved a higher proportion of recently treated patients and consequently the sensitivity of the routine Kahn test increased to 84.3 per cent, although the Wassermann reactions merely improved to 56.7 per cent. The Muller (M.B.R.) reaction was also used here and it gave a sensitivity of 59.8 per cent.

\section{RESULTS OF TESTS IN 440 EXAMINATIONS ON THE SPINAL FLUID AND BLOOD OF 200 TREATED NEURO-SYPHILITICS}

\begin{tabular}{|c|c|c|c|c|c|c|}
\hline \multicolumn{2}{|c|}{$\begin{array}{c}\text { No. of } \\
\text { examinations } \\
\text { in each group }\end{array}$} & \multicolumn{6}{|c|}{ Sensitivity of each test, per cent } \\
\cline { 2 - 7 } & Meinicke & Muller & $\begin{array}{c}\text { Routine } \\
\text { Kahn }\end{array}$ & $\begin{array}{c}\text { Presumptive } \\
\text { Kahn }\end{array}$ & Wassermann \\
\hline SPINAL & 127 & - & 59.8 & 84.3 & - & 56.7 \\
FLUID & 93 & - & - & 65.6 & - & 52.7 \\
& 220 & - & - & 61.2 & - & - \\
\hline & 83 & 94.0 & 92.8 & 89.2 & 97.6 & $71 \cdot 1$ \\
& 60 & 90.0 & 76.7 & 81.7 & - & 55.0 \\
& 55 & 85.5 & - & 40.0 & 89.1 & 33.7 \\
& 57 & 94.7 & - & - & - & 70.2 \\
& 154 & 90.9 & - & 67.5 & 93.5 & - \\
\hline
\end{tabular}

Blood test results.-As regards blood more tests were employed in varying combinations, so that six groups are required to include all the $\mathbf{4 4 0}$ examinations. The results are set out in the table above and it will be seen that although the sensitivity of each test varies a great deal (owing to variations in the material tested) the relative efficiency of each one compared with the others is constant except for the Muller test. Thus the presumptive Kahn test is always a little ahead of the Meinicke test whereas the Wassermann, when used, is consistently the least sensitive. It might be mentioned that the Meinicke test was applied to numerous fluids as well as to serums, and that the Sachs-Georgi and SachsWitebsky tests were used on 180 of the samples of spinal fluid and a similar number of blood samples; as, however, the tests were found not to be sufficiently reliable to warrant an " honourable mention" their results were omitted from the table in order not to confuse the issue.

Results such as the above have led to the adoption of the routine Kahn test as our standard test for spinal infection. Blood is examined by the routine Kahn test, the presumptive Kahn test, and the Meinicke test (microscopic and centrifuge) methods. War-time conditions have interfered with our obtaining the Meinicke antigen, hence the group of thirty-one serums not tested by the Meinicke test. Other tests such as the Kline test, or the new F.R.C. test (with certain modifications to increase sensitivity) could be used with much the same results. 


\section{THE BRITISH JOURNAL OF VENEREAL DISEASES}

\section{Tests superior to the Wassermann}

Against the policy of adopting the above standard tests might be adduced the risk of loss of specificity owing to the discarding of the Wassermann test, but as a matter of fact there need be little fear on that score, for although it is true that we have not had any false positive reactions from the Wassermann test in spinal fluids, we have not had any with the routine Kahn test either in over 500 nonsyphilitic fluids. As to blood, we have found 0.5 per cent false positive reactions with the Wassermann test in a series of 400 controls, the routine Kahn giving none in over 1,000 non-syphilitic serums. Indeed, with the exception of a few "plusminus " results in cases of glandular fever, the routine Kahn "doubtfuls" occurred in syphilitic serums and not at all in the non-syphilitic. The Meinicke test, however, in some 3,000 controls has given 1.4 per cent of false positive reactions whereas the presumptive Kahn test showed much the same result in 1,000 controls. Fortunately the two tests seem to act as a good check on one another, for in only one instance did they both give false positive reactions in the same case. To accept as correct, therefore, the positive results of both tests when in agreement with each other would appear a fairly safe procedure, one which offers no more risk than relying upon the Wassermann test alone.

The only other objection which might have to be met is that of the value of the Wassermann as a quantitative test. But as the routine Kahn results can be graded from a " one-plus" to a "four-plus" there seems little more to be achieved, especially when the combined use of the routine Kahn with the presumptive Kahn provides further grades corresponding to the combination of a doubtful and a negative routine Kahn test with a still positive presumptive Kahn test.

Routine Kahn test as minimum standard of cure.-Absolute agreement concerning the use and interpretation of tests is likely to be difficult of achievement, but surely it should be possible to recognize some test that would serve to establish a minimum standard of cure ; one, for example, that is indicative of a point beyond which the question of further therapy ceases to be an urgent matter. For this the routine Kahn test is obviously as good a choice as any; it is reasonably sensitive, highly specific, easy of performance and suitable for any laboratory. The Meinicke and the presumptive Kahn tests could then be reserved for providing additional information which might be of interest, although not essential, leading to the recognition of still further degrees of serological recovery.

\section{Tests in diagnosis}

The more sensitive tests should be accorded even more certain recognition .when it comes to a question of diagnosis, and diagnosis is by no means an unimportant matter in connexion with treated general paralytics and meningovascular syphilitics with mental involvement. Countless neuro-syphilitics, discharged after treatment, are now scattered everywhere, at home and away from home, at work and out of work. When any of them relapses (mentally at least) and is admitted as an unknown case in such a state of confusion that through lack of medical history the diagnosis has to depend upon serological tests, then the likelihood of the real nature of the disease not being missed is in direct proportion to the efficiency of the tests employed. And as long as there is not any system of central notification of venereal diseases through which old cases could be traced, the difficulty of recognizing treated general paralytics and allied types must remain a very real handicap.

\section{A concluding query}

A precise formulation of conclusions would be superfluous, but an interesting question does arise (though one connected rather with that department of pathology which is not usually regarded as physical) and it is this : what is the bias or psychological factor which accounts for such a widespread and continued use of the Wassermann test, especially for official and legal purposes, when for the past dozen years or so worker after worker has reasonably well proved that, compared with the Wasserman test, several of the flocculation tests are better, quicker, easier and cheaper? 